\title{
Geriatric or cardiac rehabilitation? Predictors of treatment pathways in advanced age patients after transcatheter aortic valve implantation
}

Sarah Eichler ${ }^{1}$, Heinz Völler ${ }^{1,2^{*}}$, Rona Reibis ${ }^{3}$, Karl Wegscheider ${ }^{4}$, Christian Butter ${ }^{5}$, Axel Harnath ${ }^{6}$ and Annett Salzwedel ${ }^{1}$

\begin{abstract}
Background: Aim of the study was to find predictors of allocating patients after transcatheter aortic valve implantation (TAVI) to geriatric (GR) or cardiac rehabilitation (CR) and describe this new patient group based on a differentiated characterization.

Methods: From 10/2013 to 07/2015, 344 patients with an elective TAVI were consecutively enrolled in this prospective multicentric cohort study. Before intervention, sociodemographic parameters, echocardiographic data, comorbidities, 6-min walk distance (6MWD), quality of life and frailty (score indexing activities of daily living [ADL], cognition, nutrition and mobility) were documented. Out of these, predictors for assignment to CR or GR after TAVI were identified using a multivariable regression model.

Results: After TAVI, 249 patients ( $80.7 \pm 5.1$ years, 59.0\% female) underwent CR $(n=198)$ or GR $(n=51)$. GR patients were older, less physically active and more often had a level of care, peripheral artery disease as well as a lower left ventricular ejection fraction. The groups also varied in 6MWD. Furthermore, individual components of frailty revealed prognostic impact: higher values in instrumental $A D L$ reduced the probability for referral to GR (OR:0.49, $p<0.001$ ), while an impaired mobility was positively associated with referral to GR (OR:3.97, $p=0.046)$. Clinical parameters like stroke (OR:0.19 of $\mathrm{GR}, p=0.038$ ) and the EuroSCORE (OR:1.04 of $\mathrm{GR}, p=0.026)$ were also predictive.

Conclusion: Advanced age patients after TAVI referred to CR or GR differ in several parameters and seem to be different patient groups with specific needs, e.g. regarding activities of daily living and mobility. Thus, our data prove the eligibility of both CR and GR settings.
\end{abstract}

Keywords: TAVI, Treatment pathways, Frailty, Geriatric rehabilitation

\footnotetext{
* Correspondence: heinz.voeller@uni-potsdam.de

1 Department of Rehabilitation Medicine, University of Potsdam, Faculty of

Health Sciences Brandenburg, Am Neuen Palais 10, D-14469 Potsdam, Germany

${ }^{2}$ Klinik am See, Rehabilitation Center for Internal Medicine, Rüdersdorf, Germany

Full list of author information is available at the end of the article
}

C C The Author(s). 2020 Open Access This article is licensed under a Creative Commons Attribution 4.0 International License, which permits use, sharing, adaptation, distribution and reproduction in any medium or format, as long as you give appropriate credit to the original author(s) and the source, provide a link to the Creative Commons licence, and indicate if changes were made. The images or other third party material in this article are included in the article's Creative Commons licence, unless indicated otherwise in a credit line to the material. If material is not included in the article's Creative Commons licence and your intended use is not permitted by statutory regulation or exceeds the permitted use, you will need to obtain permission directly from the copyright holder. To view a copy of this licence, visit http://creativecommons.org/licenses/by/4.0/. The Creative Commons Public Domain Dedication waiver (http://creativecommons.org/publicdomain/zero/1.0/) applies to the data made available in this article, unless otherwise stated in a credit line to the data. 


\section{Background}

Due to the demographic shift and the aging population, the prevalence of aortic stenosis (AS) as the most frequent valve disease is enhancing [1]. For patients having a prohibitive surgical risk, transcatheter aortic valve implantation (TAVI) has been developed as an alternative to the surgical valve replacement. Several clinical trials and registries have demonstrated the advantages and the procedural success of mid- to long-term outcomes and the procedure is now used as a golden standard $[2,3]$. Procedural and in-hospital mortality rates could be reduced and therefore, the frequency of catheter-based valve procedures is steadily increasing. It has overtaken the slightly decreased number of surgical procedures in Germany [4].

Consequently, multimorbid octogenarians with functional limitations become more present in cardiac rehabilitation (CR), whereby hospitals have to define the decision making process for the subsequent treatment and rehabilitation centers have to focus the therapy offer on the patients' individual demands such as improving postural control and combating malnutrition. After TAVI, cardiac rehabilitation already leads to significant improvements in exercise tolerance, walking capacity, muscle strength and quality of life [5-9]. Thus, official position statements promote the implementation of cardiac rehabilitation after TAVI, although there are no specific therapies yet for the individual needs of this old patient group [10, 11].

In Germany, multicomponent CR represents a wellestablished treatment for the improvement of functional and psychocognitive parameters in patients after cardiac valve procedures [12-15]. For elderly patients, there is also the option of being allocated to geriatric rehabilitation (GR) instead of indication-specific rehabilitation, if there are at least two different indications to be treated. Therefore, GR mostly accommodates multimorbid patients and aims at the recovery of physical abilities for a largely independent life in the community. The primary aim of GR is to recover an age-appropriate mobility as well as to support self-sufficiency and thus, to avoid long-term care [16-18].

Regarding multimorbid and geriatric patients, the term frailty is often brought up in research, but is not settled as a definite assessment yet. The Valve Academic Research Consortium has underlined the relevance of frailty with defining it as multicomponent including the dimensions of loss of independence, exhaustion, slowness, wasting and malnutrition, poor endurance and inactivity as well as weakness [19]. However, frailty hasn't been considered as an own cardiovascular risk factor and has also not been included into traditional risk scores like EuroSCORE. Furthermore, several different approaches for measuring frailty have been described.
Two indices seem to prevail in clinical studies [20,21]. Nevertheless, the significance of the indices or its single dimensions for the care pathway after TAVI hasn't been focused enough in research.

The aim of the study was to characterize older patients after TAVI and to identify predictors of allocating to either geriatric or cardiac rehabilitation under consideration of frailty related components. Our research hypothesis is the following: We assume that patients referred to GR differ to those referred to CR in several physical and psychological domains.

\section{Methods}

\section{Study setting and participants}

In this prospective multicenter cohort study, 635 patients assigned for elective TAVI, which was the only inclusion criterion, were screened in two German heart centers between October 2013 and July 2015. Exclusion criteria were patient refusal, lack of capacity to give informed consent due to poor health status, logistical reasons such as shift of intervention or cancellation of the intervention.

\section{Baseline measures}

Before elective TAVI, sociodemographic data (e. g. age and gender), comorbidities (e. g. stroke/transient ischemic attack [TIA], peripheral artery disease [PAD], diabetes mellitus, coronary artery disease, chronic obstructive pulmonary disease and chronic kidney disease), subjective evaluation of physical activity (volume per week), level of care and echocardiographic parameters (e. g. left ventricular ejection fraction [LVEF] and transaortic gradients) as well as the logistic EuroSCORE were documented in the participating heart centers.

Further, for the quantification of the performance status a standardized 6-min walk test (6MWT) according to current guidelines of the American Thoracic Society [22] based on a distance measuring device was performed. In addition, health related quality of life was assessed by using the questionnaire Short Form 12 (SF12) [23] with its physical and mental component summaries (PCS and MCS). Anxiety and depression were determined using the Hospital Anxiety and Depression Scale (HADS) [24], and frailty according to the index of Stortecky et al. [25] This Frailty-Index included the Mini Mental State Examination (MMSE), the short form of the Mini Nutritional Assessment Short Form (MNA-SF), Activities of Daily Living (ADL), Instrumental Activities of Daily Living (IADL), Timed Up and Go Test (TUG) and a subjective mobility disability (defined as a decreased frequency of walking $200 \mathrm{~m}$ and/or of climbing stairs). The index was summarized with the following allocations: 2 points were assigned if MMSE was $<21$ points, and 1 point was assigned for each of the 
following: MMSE $\geq 21$ and $<27$ points, MNA $<12$ points, ADL $\geq 1$ limited activity, IADL $\geq 1$ limited activity, TUG $\geq 20 \mathrm{~s}$, and a positive subjective mobility disability. Hence, the Frailty-Index ranged from 0 to 7 points and can be categorized at $\geq 3$ points (frail) vs. $<3$ points (non-frail).

The primary endpoint was the assignment to either GR or CR in patients after TAVI, decided by the medical staff in the heart centers. The information was derived on subsequent phone calls with the patients and/or their relatives.

\section{Statistics}

Continuous variables are expressed as means \pm standard deviation (SD), and categorical variables as absolute values and percentages. Comparisons between groups were performed using the t-test and the chi-square test, respectively. Predictors of pathways (e. g. GR vs. CR) were identified using a multivariable logistic regression model. We started with a full model containing all available covariates and performed a backwards selection to keep only significant effects in the model. Effects with a $p$-value of less than 0.05 (two-sided) were considered significant. Calculations were carried out using SPSS 25.0 (IBM, Chicago, IL, USA) and Stata (StataCorp. 2017. Stata Statistical Software: Release 15. College Station, TX: StataCorp LLC).

\section{Results}

\section{Baseline data (Total cohort)}

After the exclusion of 291 patients mainly due to patient refusal, 344 patients scheduled for TAVI could be enrolled prior to the procedure. $333(96.8 \%)$ patients were alive at discharge, whereby 198 (59.5\%) patients underwent CR after the intervention and 51 (15.3\%) patients were allocated to GR. 52 (15.1\%) patients rejected rehabilitation and were discharged home (Fig. 1). Thus, data of 249 patients in CR and GR were analyzed.

The patients (mean age $80.7 \pm 5.1$ years, 147 (59.0\%) women) were considered multimorbid with having $2.2 \pm$ 1.3 comorbidities. Moreover, almost half of the patients (42.6\%) suffered from diabetes mellitus. Most of the patients $(83.1 \%)$ did not have a level of care and 110 patients $(44.2 \%)$ described themselves as very active with more than 150 min of physical activity per week.

Before TAVI, the echocardiographic data showed a mean LVEF of $54.5 \pm 10.9 \%$ as well as a maximum and mean transvalvular aortic gradient of $71.6 \pm 24.9$ and $44.9 \pm 16.5$ $\mathrm{mmHg}$, respectively. Describing the surgical risk, patients showed a logistic EuroSCORE of $16.5 \pm 12.1 \%$. (Table 1). Also prior to TAVI, the patients achieved a 6-min walk distance (6MWD) of $239.6 \pm 117.9 \mathrm{~m}$ and needed a mean walking time of $14.2 \pm 7.3 \mathrm{~s}$. in the TUG. With a mean Frailty-Index of $2.4 \pm 1.6$ points, the investigated population is overall to be classified as non-frail (Table 2).

TAVI was performed under a short period of general anesthesia in $83(33.3 \%)$ patients and local anesthesia in $166(66.7 \%)$ patients, whereby the main access route was through the femoral artery in 235 (94.4\%) patients and via a left-sided small anterolateral minithoracotomy in 14 (5.6\%) patients. A Medtronic CoreValve Evolut $\mathrm{R}$ Prosthesis (Medtronic Inc., Minnesota, USA) was implanted in $165(66.3 \%)$ patients, an Edwards SAPIEN ${ }^{\text {ma }}$

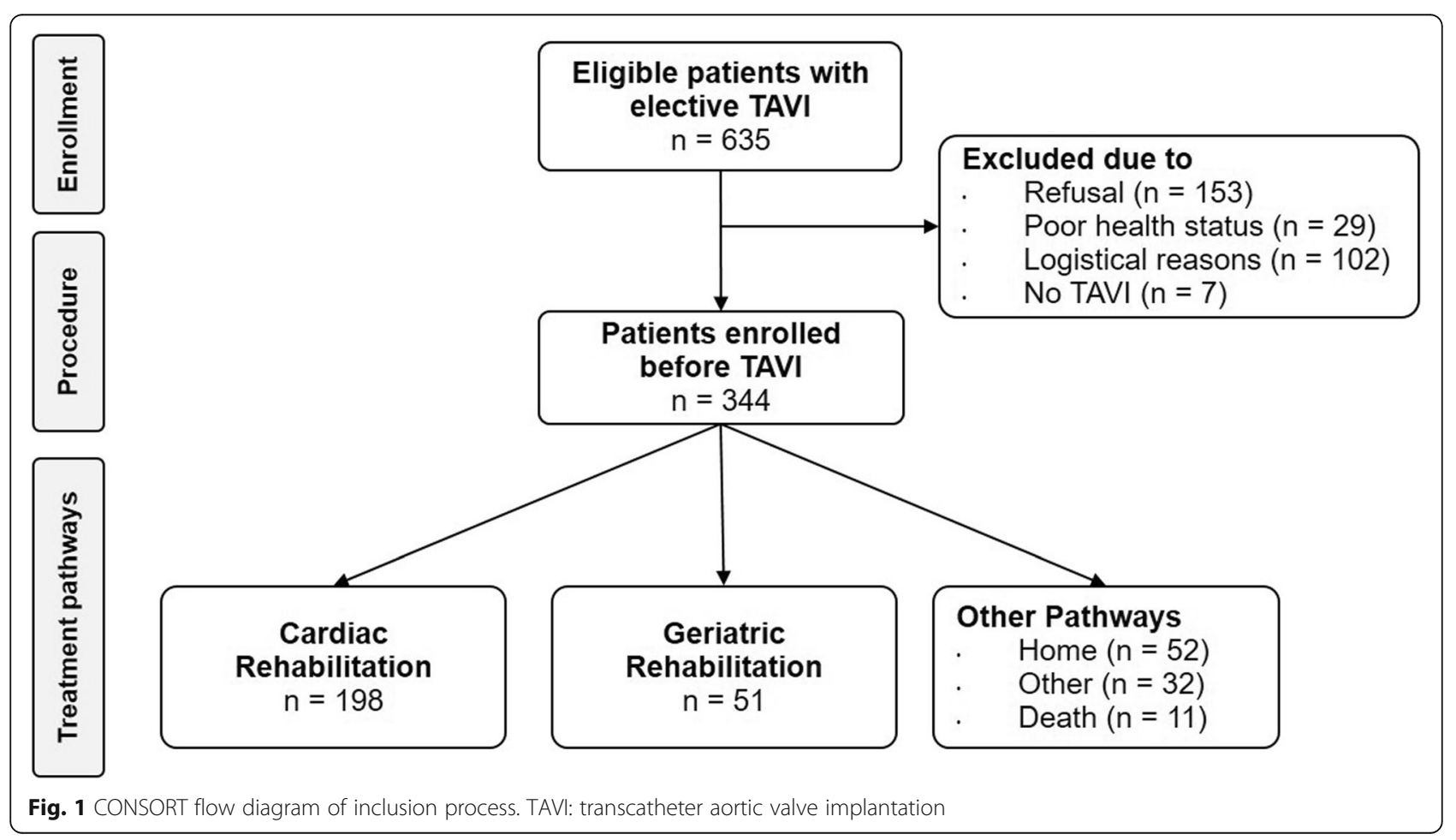


Table 1 Baseline characteristics (Total cohort, cardiac vs. geriatric rehabilitation patients)

\begin{tabular}{|c|c|c|c|c|}
\hline & $\begin{array}{l}\text { Total cohort } \\
(n=249)\end{array}$ & $\begin{array}{l}\text { CR } \\
(n=198)\end{array}$ & $\begin{array}{l}\mathrm{GR} \\
(n=51)\end{array}$ & $p$-value \\
\hline \multicolumn{5}{|l|}{ Patient characteristics } \\
\hline Age, years & $80.7 \pm 5.1$ & $80.3 \pm 4.9$ & $82.6 \pm 5.4$ & 0.003 \\
\hline Sex, male & $102(41.0)$ & $87(43.9)$ & $15(29.4)$ & 0.060 \\
\hline NYHA III/IV & $241(96.8)$ & $190(96.0)$ & $51(100.0)$ & 0.145 \\
\hline $\mathrm{BMl}, \mathrm{kg} / \mathrm{m}^{2}$ & $28.0 \pm 4.8$ & $28.0 \pm 4.6$ & $27.8 \pm 5.4$ & 0.818 \\
\hline Physical activity (subjective) & & & & $<0.001$ \\
\hline Inactive (< 90 min/week) & $75(30.1)$ & $45(22.7)$ & $30(58.8)$ & \\
\hline Active ( $\geq 90-150 \mathrm{~min} /$ week) & $64(25.7)$ & $59(29.8)$ & $5(9.8)$ & \\
\hline Very active (> $150 \mathrm{~min} /$ week) & $110(44.2)$ & $94(47.5)$ & $16(31.4)$ & \\
\hline Level of care & & & & $<0.001$ \\
\hline None & $207(83.1)$ & $181(91.4)$ & $26(51.0)$ & \\
\hline 1 & $36(14.5)$ & $16(8.1)$ & $20(39.2)$ & \\
\hline 2 & $6(2.4)$ & $1(0.5)$ & $5(9.8)$ & \\
\hline Diabetes mellitus & $106(42.6)$ & $82(41.4)$ & $24(47.1)$ & 0.467 \\
\hline Log. EurOSCORE, \% & $16.5 \pm 12.1$ & $15.0 \pm 10.9$ & $22.5 \pm 14.6$ & 0.001 \\
\hline Comorbidities, no. & $2.2 \pm 1.3$ & $2.1 \pm 1.2$ & $2.5 \pm 1.4$ & 0.051 \\
\hline CAD & $159(63.9)$ & $124(62.6)$ & 35 (68.6) & 0.426 \\
\hline COPD & $47(18.9)$ & $33(16.7)$ & $14(27.5)$ & 0.079 \\
\hline PAD & $57(22.9)$ & $37(18.7)$ & $20(39.2)$ & 0.002 \\
\hline CKD & $114(45.8)$ & $85(42.9)$ & $29(56.9)$ & 0.075 \\
\hline Stroke/TIA & $34(13.7)$ & $30(15.2)$ & $4(7.8)$ & 0.175 \\
\hline Length of hospital stay, days & $11.1 \pm 4.3$ & $10.2 \pm 3.8$ & $14.6 \pm 4.6$ & $<0.001$ \\
\hline \multicolumn{5}{|l|}{ ECG and Echocardiography } \\
\hline Rhythm & & & & 0.280 \\
\hline Sinus rhythm & $144(57.8)$ & $119(60.0)$ & $25(49.0)$ & \\
\hline Atrial fibrillation & $98(39.4)$ & $73(36.9)$ & $25(49.0)$ & \\
\hline Pacemaker & $7(2.8)$ & $6(3.1)$ & $1(2.0)$ & \\
\hline LVEF, \% & $54.5 \pm 10.9$ & $55.4 \pm 10.3$ & $51.2 \pm 12.3$ & 0.027 \\
\hline Left atrium, mm & $45.6 \pm 6.4$ & $45.4 \pm 6.2$ & $46.2 \pm 6.8$ & 0.463 \\
\hline LVEDD & $48.2 \pm 8.3$ & $47.8 \pm 8.0$ & $49.6 \pm 9.2$ & 0.177 \\
\hline LVPW & $13.4 \pm 2.9$ & $13.2 \pm 2.6$ & $13.7 \pm 3.8$ & 0.369 \\
\hline IVS & $13.4 \pm 2.7$ & $13.4 \pm 2.6$ & $13.4 \pm 3.1$ & 0.944 \\
\hline Transaortic $\Delta \mathrm{P}_{\text {mean }}(\mathrm{mmHg})$ & $44.9 \pm 16.5$ & $44.5 \pm 15.8$ & $46.3 \pm 19.2$ & 0.544 \\
\hline Transaortic $\Delta \mathrm{P}_{\max }(\mathrm{mmHg})$ & $71.6 \pm 24.9$ & $71.1 \pm 24.0$ & $73.6 \pm 28.2$ & 0.575 \\
\hline
\end{tabular}

Categorical variables are presented in $\mathrm{n}(\%)$, metric variables in mean $\pm \mathrm{SD}$

Abbreviations: $C R$ cardiac rehabilitation, $G R$ geriatric rehabilitation, $C O P D$ chronic obstructive pulmonary disease, $P A D$ peripheral artery disease, $C K D$ chronic kidney disease, TIA transient ischemic attack, ECG electrocardiography, LVEF left ventricular ejection fraction, LVEDD left ventricular enddiastolic diameter, LVPW left ventricular posterior wall, IVS interventricular septum

transcatheter heart valve (Edwards Lifesciences LLC, Irvine, CA, USA) in 54 (21.7\%) patients. After TAVI, the patients stayed in hospital for $11.1 \pm 4.3$ days.

\section{Cardiac vs. geriatric rehabilitation patients}

In the group comparison, patients allocated to GR were older $(82.6 \pm 5.4$ vs. $80.3 \pm 4.9$ years; $p=0.003)$ and less physically active $(p<0.001)$ than patients referred to CR. Besides, more of the patients referred to GR had a level of care $(p<0.001)$ and showed a higher surgical risk $(22.5 \pm 14.6$ vs. $15.0 \pm 10.9 \%$; $p=0.001)$ before TAVI.

In addition, the patients differed with regard to comorbidities and clinical parameters as more of the GR patients had PAD (39.2 vs. 18.7\%; $p=0.002)$ and a 
Table 2 Baseline assessments (Total cohort, cardiac vs. geriatric rehabilitation patients)

\begin{tabular}{|c|c|c|c|c|}
\hline Assessments & $\begin{array}{l}\text { Total cohort } \\
(n=249)\end{array}$ & $\begin{array}{l}\text { CR } \\
(n=198)\end{array}$ & $\begin{array}{l}\mathrm{GR} \\
(n=51)\end{array}$ & $p$-value \\
\hline 6MWD, m & $239.6 \pm 117.9$ & $250.6 \pm 115.8$ & $180.3 \pm 113.5$ & 0.006 \\
\hline \multicolumn{5}{|l|}{ Health related quality of Life } \\
\hline SF-12 PCS, points & $33.1 \pm 10.1$ & $33.7 \pm 9.8$ & $30.9 \pm 11.0$ & 0.085 \\
\hline SF-12 MCS, points & $50.5 \pm 10.4$ & $50.8 \pm 10.5$ & $49.1 \pm 9.8$ & 0.285 \\
\hline \multicolumn{5}{|l|}{ Emotional Status } \\
\hline HADS Anxiety, points & $5.7 \pm 3.9$ & $5.9 \pm 3.8$ & $5.9 \pm 4.1$ & 0.176 \\
\hline HADS Depression, points & $5.6 \pm 3.7$ & $5.4 \pm 3.5$ & $6.5 \pm 4.1$ & 0.050 \\
\hline Frailty-Index, points & $2.4 \pm 1.6$ & $2.1 \pm 1.4$ & $3.8 \pm 1.7$ & $<0.001$ \\
\hline Frailty-Index, $\geq 3$ pts. & $106(42.6)$ & $67(33.8)$ & $39(76.5)$ & $<0.001$ \\
\hline MMSE, points & $27.1 \pm 2.7$ & $27.3 \pm 2.6$ & $26.3 \pm 3.3$ & 0.045 \\
\hline MNA-SF, points & $11.7 \pm 2.3$ & $11.9 \pm 2.1$ & $11.1 \pm 2.9$ & 0.053 \\
\hline$A D L$, points & $94.2 \pm 11.7$ & $97.3 \pm 6.8$ & $82.2 \pm 17.8$ & $<0.001$ \\
\hline$I A D L$, points & $7.0 \pm 1.6$ & $7.4 \pm 1.1$ & $5.3 \pm 2.0$ & $<0.001$ \\
\hline TUG, sec. & $14.2 \pm 7.3$ & $13.0 \pm 6.5$ & $19.0 \pm 8.5$ & $<0.001$ \\
\hline Subjective mobility disability & $191(76.7)$ & $150(75.8)$ & $41(80.4)$ & 0.485 \\
\hline
\end{tabular}

Categorical variables are presented in $\mathrm{n}(\%)$, metric variables in mean $\pm \mathrm{SD}$

Abbreviations: $C R$ cardiac rehabilitation, GR geriatric rehabilitation, 6MWD 6-min walk distance, SF-12 Short Form 12, PCS physical component summary, MCS mental component summary, HADS Hospital Anxiety and Depression Scale, MMSE Mini Mental State Exam, MNA-SF Mini Nutritional Assessment Short Form, ADL

Activities of Daily Living, IADL Instrumental Activities of Daily Living, TUG Timed Up and Go Test

significantly lower LVEF $(51.2 \pm 12.3$ vs. $55.4 \pm 10.3 \%$; $p=0.027$ ). Patients referred to GR stayed in hospital for more days than the CR patients (Table 1).

The groups also varied in functional parameters. The GR patients achieved a lower 6MWD $(180.3 \pm 113.5$ vs. $250.6 \pm 115.8 \mathrm{~m} ; p=0.006)$ as well as a higher depression score $(6.5 \pm 4.1$ vs. $5.4 \pm 3.5$ points; $p=0.050)$ and a higher overall Frailty-Index $(3.8 \pm 1.7$ [frail] vs. $2.1 \pm 1.4$ points [non-frail]; $p<0.001$ ). Also, the CR and GR patients differed significantly in almost every single component of the Frailty-Index (Table 2).

\section{Predictors of treatment pathways}

In the multivariable regression model, the Frailty-Index as such was not predictive for the treatment pathway. Individual components such as IADL and TUG revealed prognostic impact. Put differently, the chance of being referred to GR was reduced by $51 \%$ per one point more in the IADL in favour to CR, while the chance to be referred to GR was 3.97 times higher when the patients needed more or equal to $20 \mathrm{~s}$ in the TUG versus the patients who needed less than $10 \mathrm{~s}$.

Similarly, other factors were prognostically relevant. One point more in the PCS of the SF-12 increased the chance for being referred to GR by $7 \%$. The self-assessed physical activity compared to inactivity reduced the probability for GR referral by $79 \%$. Likewise, a patient with level of care 1 had a 4.45 times higher odds for GR than a patient without level of care.
Finally, clinical parameters were predictive as well. Having had an previous stroke/TIA reduced the chance of being referred to GR by $81 \%$, whereas the odds were $4 \%$ higher per $1 \%$ more in the logistic EuroSCORE in favour GR (Fig. 2).

\section{Discussion}

In our analysis, we showed that advanced age patients with transcatheter aortic valve implantation differ with regard to on cardiac or geriatric rehabilitation referral. Especially, single components of the Frailty-Index such as lower instrumental activities of daily living and mobility were predictive parameters for the referral to GR. Additionally, health-related quality of life as well as selfassessed physical activity and level of care seem to be of great importance. Also, clinical parameters such as a previous stroke/TIA and the logistic EuroSCORE, initially used to estimate the operative risk in surgical patients, were associated with the referral to cardiac or geriatric rehabilitation.

Concerning the self-assessed level of activity and the level of care, both parameters seem to be conclusive in terms of the decision for CR or GR referral. As the aim of geriatric rehabilitation is the recovery of an ageappropriate mobility and self-sufficiency and thus in the broadest sense the avoidance of long-term care [17], patients who already have a level of care could benefit from this rehabilitation approach. 


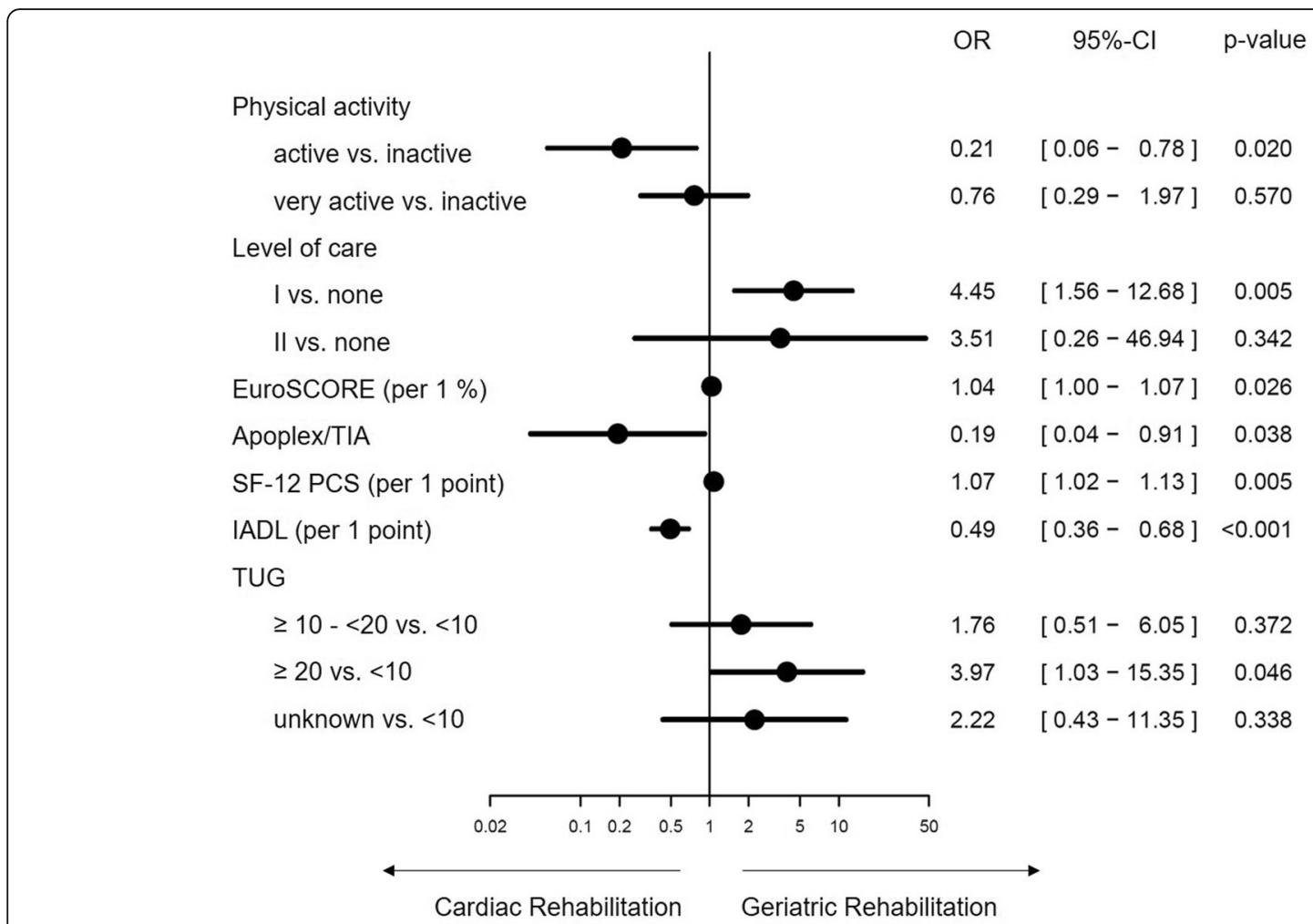

Fig. 2 Predictors of treatment pathways in patients after TAVI. OR: Odds Ratio, Cl: confidence interval, TIA: transient ischemic attack, SF-12: Short Form 12, PCS: physical component summary, IADL: Instrumental Activities of Daily Living, TUG: Timed Up and Go Test. Apoplex is synonymous with previous stroke. Exemplary explanation: The odds of being referred to geriatric rehabilitation is 4.45 times higher in patients with a level of care 1 versus patients with no level of care.

As for the results of the clinical parameters, the patients who have had a previous stroke were more likely to be assigned to CR, which occurs to be interesting, because we suggested it to be the other way round. It could result from a good recovery and continuous guideline-oriented neurological/cardiological care after the stroke and therefore a good outcome of the intervention. On the contrary, the fact that higher values in the EuroSCORE and therefore a higher surgical risk lead to an enhanced probability of GR referral corresponds to the expectations.

Combining clinical as well as other dimensions, frailty is a geriatric syndrome that is characterized by a vulnerability status with declining function and physiological reserves [26]. Due to the demographic shift, a recent call to action from the European Association of Preventive Cardiology Cardiac Rehabilitation Section promotes the investigation of frail patients also in cardiac rehabilitation settings and recommends to become familiar with some of the tools to recognize and evaluate the severity of this condition [27]. In addition, a recent review concludes that frailty assessments in CR settings should be based on functional, objective tests and should have similar components as tools for risk assessment (e. g. mobility, muscle mass and strength, independence in daily living, cognitive function, nutrition as well as anxiety and depression evaluation) [28].

The results of our study support this importance. The patients were multimorbid with a mean of two comorbidities. There is no doubt that frailty consists of many single domains, but we have to state that the calculation or summary of an overall index for frailty does not seem to be necessary since it doesn't reveal prognostic impact. Single components such as instrumental activities of daily living or mobility reveal strong prediction on their own for the referral to either geriatric or cardiac rehabilitation and thus for the characterization of this new patient group. This conforms to results of an own study where mobility and nutrition had a prognostic relevance for one-year allcause mortality in patients after TAVI [29].

Based on our findings, we raise the question if frailty might be more a geriatric than a cardiac rehabilitation topic. Our results show that $34 \%$ of the patients undergoing cardiac rehabilitation can be considered frail, whereas $77 \%$ of the patients referred to geriatric rehabilitation show a positive frailty according to the index we used. This leads to the assumption that the "real" frail and needy patient does not arrive in CR, but in GR. Consequently, this means that frailty is definitely worth 
working on in CR, but might be even more important in GR settings. Supporting this thesis, recent research is more and more focusing on investigations of frailty in geriatric rehabilitation and there is an approach to bridge the fields of geriatric medicine and rehabilitation by recognizing the interwoven concepts of multimorbidity, function and frailty [30]. It is also stated that frailty even measured by routinely collected data is feasible and predictive of poor outcomes [31]. Further, other studies about frailty related factors in geriatric rehabilitation conclude that variables such as physical factors such as slow gait speed [32] as well as cognitive and muscular function [33] could be relevant for functional improvement. There is also evidence that geriatric rehabilitation in older patients with cardiovascular disease is feasible [34], whereby the collaboration of geriatric and cardiac rehabilitation scientists and doctors will be a challenging task within the next years. Besides, it is necessary to investigate and to identify the patients that are not frail yet, but might be in a pre-frail state. The upcoming question might be if they are in better hands in either geriatric or cardiac rehabilitation.

Our investigated GR and CR patients also differ in functional parameters such as 6-min walk distance and Timed Up and Go Test. The latter even revealed significance in the multivariable analysis. From the clinical point of view, this could be due to the fact that many GR patients ( $40 \%$ vs. $20 \%$ of CR patients) suffered from peripheral artery disease, which could have influenced walking or the movements of the patients. Thus, for achieving results more considerable, other assessments that can be performed independently from the legs must be investigated. Hand grip strength, for instance, can be measured quantitatively using a hand dynamometer. It has already been recommended from the European Working Party on Sarcopenia in Older People and is proposed as a useful assessment of physical performance that is able to determine clinically significant changes [35]. Further, hand grip strength is associated with cardiovascular mortality and can provide valuable prognostic information above and beyond traditional assessments and should therefore be considered for implementation in clinical practice [36].

All in all, the differences between patients referred to cardiac and geriatric rehabilitation setting, respectively, prove the heterogeneity of this population and, finally, the eligibility of both settings. As the new elderly patient group is more diverse than one might think, there should be an overlap between CR and GR. GR should also offer cardiological care and vice versa.

\section{Limitations}

The present study has certain limitations. First, participation was voluntary and thus not without a selection bias, particularly in patients with higher risk profiles, who could have changed the result due to their worse condition after the intervention. It can also be assumed that additionally to this further mentioned selection bias, patients who want to undergo rehabilitation after their clinical stay are different to those who want to go home, who we didn't consider in our study. Additionally, we do not take into account the post-procedural echocardiographic data regarding the quality of the valve implantation or the different types of valves, which can affect the clinical outcome. Although the underlying Frailty Index captures components such as nutrition, it would be of interest to differentiate between lean and fat body mass as an index of sarcopenia. There are also many indices that consider e.g. serum albumin to have a more differentiated description of the patients. This would require a further approach to characterizing TAVI patients and may be advocated for detailed research.

\section{Conclusion}

Advanced age patients after transcatheter aortic valve implantation referred to cardiac or geriatric rehabilitation differ in single components of the Frailty-Index such as instrumental activities of daily living and mobility were objected as predictive parameters for the subsequent postinterventional care. Additionally, the evaluation of health related quality of life as well as self-evaluated physical activity and level of care seem to be of great importance. Also, clinical parameters such as a previous stroke/TIA and the logistic EuroSCORE were associated with the assignment. The patients seem to be different with specific needs. Thus, our data prove the eligibility of both CR and GR settings.

\section{Abbreviations}

AS: Aortic stenosis; 6MWD: 6-min walk distance; 6MWT: 6-min walk test; ADL: Activities of daily living, i CR: Cardiac rehabilitation; GR: Geriatric rehabilitation; HADS: Hospital anxiety and depression scale;

IADL: Instrumental activities of daily living; LVEF: Left ventricular ejection fraction; MCS: Mental component summary; MMSE: Mini mental state examination; MNA-SF: Mini nutritional assessment short form; OR: Odds ratio; PAD: Peripheral artery disease; PCS: Physical component summary; SD: Standard deviation; SF-12: Short form 12; TAVI: Transcatheter aortic valve implantation; TIA: Transient ischemic attack; TUG: Timed up and go test

\section{Acknowledgements}

We are grateful to all patients for their commitment and patience as well as to all physicians and study nurses in the participating heart centers.

Parts of the results were presented at the ISPRM World Congress in Orlando, Florida in March 2020

\section{Authors' contributions}

SE, AS, RR and HV designed the study, SE wrote the first draft of the manuscript. $\mathrm{AH}$ and $\mathrm{CB}$ enrolled the patients in the heart centers and coordinated the referral to the rehabilitation clinics. KW conducted the statistical analysis. All authors read and approved the final manuscript.

Funding

Not applicable. 


\section{Availability of data and materials}

The datasets used and/or analyzed during the current study are available from the corresponding author on reasonable request. All data generated or analyzed during this study are included in this published article.

\section{Ethics approval and consent to participate}

The study protocol was approved by the ethics committee of the University of Potsdam (No. 35/2013). All patients gave their written consent to participate in the investigation. Data protection rules were closely observed and patient data were processed anonymously.

\section{Consent for publication}

Not applicable.

\section{Competing interests}

The author reports no conflicts of interest in this work.

\begin{abstract}
Author details
'Department of Rehabilitation Medicine, University of Potsdam, Faculty of Health Sciences Brandenburg, Am Neuen Palais 10, D-14469 Potsdam, Germany. ${ }^{2}$ Klinik am See, Rehabilitation Center for Internal Medicine, Rüdersdorf, Germany. ${ }^{3}$ Cardiological Outpatient Clinic Am Park Sanssouci, Potsdam, Germany. ${ }^{4}$ Department of Medical Biometry and Epidemiology, University Medical Center, Hamburg-Eppendorf, Germany. ${ }^{5}$ Heart Center Brandenburg, Medical School Brandenburg, Bernau, Germany. ${ }^{6}$ Sana Heart-Center Cottbus, Cottbus, Germany.
\end{abstract}

Received: 1 August 2019 Accepted: 29 March 2020

\section{Published online: 06 April 2020}

\section{References}

1. Zahn R, Werner N, Gerckens U, Linke A, Sievert H, Kahlert P, Hambrecht R, Sack S, Abdel-Wahab M, Hoffmann E, Zeymer U, Schneider S. Five-year follow-up after transcatheter aortic valve implantation for symptomatic aortic stenosis. Heart. 2017;103(24):1970-6. https://doi.org/10.1136/heartjnl2016-311004

2. Siontis GC, Praz F, Pilgrim T, Mavridis D, Verma S, Salanti G, Sondergaard L, Juni P, Windecker S. Transcatheter aortic valve implantation vs. surgical aortic valve replacement for treatment of severe aortic stenosis: a metaanalysis of randomized trials. European heart journal. 2016. https://doi.org/ 10.1093/eurheartj/ehw225

3. Smith CR, Leon MB, Mack MJ, Miller DC, Moses JW, Svensson LG, Tuzcu EM, Webb JG, Fontana GP, Makkar RR, Williams M, Dewey T, Kapadia S, Babaliaros V, Thourani VH, Corso P, Pichard AD, Bavaria JE, Herrmann HC, Akin JJ, Anderson WN, Wang D, Pocock SJ, Investigators PT. Transcatheter versus surgical aortic-valve replacement in high-risk patients. N Engl J Med. 2011;364(23):2187-98. https://doi.org/10.1056/NEJMoa1103510

4. Gaede L, Blumenstein J, Kim W-K, Liebetrau C, Dörr O, Nef H, Hamm C, Elsässer A, Möllmann H (2017) Trends in aortic valve replacement in Germany in 2015: transcatheter versus isolated surgical aortic valve repair. Clinical Research in Cardiology:1-9. doi:https://doi.org/10.1007/s00392-0161070-1

5. Voller H, Salzwedel A, Nitardy A, Buhlert H, Treszl A, Wegscheider K. Effect of cardiac rehabilitation on functional and emotional status in patients after transcatheter aortic-valve implantation. Eur J Prev Cardiol. 2015;22(5):568-74. https://doi.org/10.1177/2047487314526072

6. Eichler S, Salzwedel A, Reibis R, Nothroff J, Harnath A, Schikora M, Butter C, Wegscheider K, Völler H. Multicomponent cardiac rehabilitation in patients after transcatheter aortic valve implantation: predictors of functional and psychocognitive recovery. Eur J Prev Cardiol. 2017;24(3):257-64. https://doi. org/10.1177/2047487316679527

7. Russo N, Compostella L, Tarantini G, Setzu T, Napodano M, Bottio T, D'Onofrio A, Isabella G, Gerosa G, Iliceto S, Bellotto F. Cardiac rehabilitation after transcatheter versus surgical prosthetic valve implantation for aortic stenosis in the elderly. Eur J Prev Cardiol. 2014;21(11):1341-8. https://doi. org/10.1177/2047487313494029

8. Pressler A, Christle JW, Lechner B, Grabs V, Haller B, Hettich I, Jochheim D, Mehilli J, Lange R, Bleiziffer S, Halle M. Exercise training improves exercise capacity and quality of life after transcatheter aortic valve implantation: a randomized pilot trial. Am Heart J. 2016;182:44-53. https://doi.org/10.1016/j. ahj.2016.08.007
9. Ribeiro GS, Melo RD, Deresz LF, Dal Lago P, Pontes MR, Karsten M. Cardiac rehabilitation programme after transcatheter aortic valve implantation versus surgical aortic valve replacement: systematic review and metaanalysis. European journal of preventive cardiology. 2017 : 2047487316686442. https://doi.org/10.1177/2047487316686442

10. Mezzani A, Hamm LF, Jones AM, McBride PE, Moholdt T, Stone JA, Urhausen A, Williams MA, European Association for Cardiovascular P, Rehabilitation, American Association of C, Pulmonary R, Canadian Association of Cardiac R. Aerobic exercise intensity assessment and prescription in cardiac rehabilitation: a joint position statement of the European Association for Cardiovascular Prevention and Rehabilitation, the American Association of Cardiovascular and Pulmonary Rehabilitation and the Canadian Association of Cardiac Rehabilitation. Eur J Prev Cardiol. 2013;20(3):442-67. https://doi. org/10.1177/2047487312460484

11. Piepoli MF, Hoes AW, Agewall S, Albus C, Brotons C, Catapano AL, Cooney MT, Corra U, Cosyns B, Deaton C, Graham I, Hall MS, Hobbs FD, Lochen ML, Lollgen H, Marques-Vidal P, Perk J, Prescott E, Redon J, Richter DJ, Sattar N, Smulders Y, Tiberi M, van der Worp HB, van Dis I, Verschuren WM, Authors/ Task Force M. 2016 European guidelines on cardiovascular disease prevention in clinical practice: the sixth joint task force of the European Society of Cardiology and Other Societies on cardiovascular disease prevention in clinical practice (constituted by representatives of 10 societies and by invited experts) developed with the special contribution of the European Association for Cardiovascular Prevention \& rehabilitation (EACPR). Eur Heart J. 2016;37(29):2315-81. https://doi.org/10.1093/eurheartj/ehw106

12. Butchart EG, Gohlke-Barwolf C, Antunes MJ, Tornos $P$, De Caterina R, Cormier B, Prendergast B, lung B, Bjornstad H, Leport C, Hall RJ, Vahanian A, Working Groups on Valvular Heart Disease T, Cardiac R, Exercise Physiology ESoC. Recommendations for the management of patients after heart valve surgery. Eur Heart J. 2005;26(22):2463-71. https://doi.org/10.1093/eurheartj/ehi426

13. Horstkotte $D$, Lengyel M, Mistiaen WP, Voller H, Reibis R, Bogunovic N, Faber L, Hering D, Piper C, Working Group Infection TE, Bleeding, Society of Heart Valve D. Recommendations for post-discharge patient follow up after cardiac valve interventions: a position paper. The Journal of heart valve disease. 2007;16(6):575-89.

14. Kiel MK. Cardiac rehabilitation after heart valve surgery. PM R. 2011;3(10): 962-7. https://doi.org/10.1016/j.pmrj.2011.06.007

15. Butter C, Groß J, Haase-Fielitz A, Sims H, Deutsch C, Bramlage P, Neuss M. Impact of rehabilitation on outcomes after TAVl: a preliminary study. J Clin Med. 2018;7(10):326. https://doi.org/10.3390/jcm7100326

16. Freidel K, Linck-Eleftheriadis S, Rohrig B, Schilling S, Heckmann J. A 10-year evaluation of geriatric rehabilitation in Rhineland-Palatinate. Z Gerontol Geriatr. 2017:50(4):365-73. https://doi.org/10.1007/s00391-016-1101-6

17. Kwetkat $A$, Lehmann $T$, Wittrich $A$. Early geriatric rehabilitation: an opportunity for the oldest old. Z Gerontol Geriatr. 2014;47(5):372-8. https:// doi.org/10.1007/s00391-014-0660-7

18. Diekmann $\mathrm{R}$, Wojzischke J. The role of nutrition in geriatric rehabilitation. Curr Opin Clin Nutr Metab Care. 2018;21(1):14-8. https://doi.org/10.1097/ mco.0000000000000433

19. Kappetein AP, Head SJ, Genereux P, Piazza N, van Mieghem NM, Blackstone EH, Brott TG, Cohen DJ, Cutlip DE, van Es GA, Hahn RT, Kirtane AJ, Krucoff MW, Kodali S, Mack MJ, Mehran R, Rodes-Cabau J, Vranckx P, Webb JG, Windecker S, Serruys PW, Leon MB. Updated standardized endpoint definitions for transcatheter aortic valve implantation: the valve academic research Consortium-2 consensus document. Eur Heart J. 2012;33(19):240318. https://doi.org/10.1093/eurheartj/ehs255

20. Rockwood K, Mitnitski A. Frailty in relation to the accumulation of deficits. J Gerontol A Biol Sci Med Sci. 2007;62(7):722-7.

21. Fried LP, Tangen CM, Walston J, Newman AB, Hirsch C, Gottdiener J, Seeman T, Tracy R, Kop WJ, Burke G, MA MB, Cardiovascular Health Study Collaborative Research G. Frailty in older adults: evidence for a phenotype. J Gerontol A Biol Sci Med Sci. 2001;56(3):M146-56.

22. Laboratories ACoPSfCPF (2002) ATS statement: guidelines for the six-minute walk test. Am J Respir Crit Care Med 166 (1):111-117. doi:https://doi.org/10. 1164/ajrccm.166.1.at1102

23. Ware J Jr, Kosinski M, Keller SD. A 12-item short-form health survey: construction of scales and preliminary tests of reliability and validity. Med Care. 1996;34(3):220-33.

24. Herrmann C. International experiences with the hospital anxiety and depression scale--a review of validation data and clinical results. J Psychosom Res. 1997;42(1):17-41. 
25. Stortecky S, Schoenenberger AW, Moser A, Kalesan B, Juni P, Carrel T, Bischoff S, Schoenenberger CM, Stuck AE, Windecker S, Wenaweser P. Evaluation of multidimensional geriatric assessment as a predictor of mortality and cardiovascular events after transcatheter aortic valve implantation. JACC Cardiovascular interventions. 2012;5(5):489-96. https:// doi.org/10.1016/j.jcin.2012.02.012

26. Morley JE, Vellas B, van Kan GA, Anker SD, Bauer JM, Bernabei R, Cesari M, Chumlea WC, Doehner W, Evans J, Fried LP, Guralnik JM, Katz PR, Malmstrom TK, McCarter RJ, Gutierrez Robledo LM, Rockwood K, von Haehling S, Vandewoude MF, Walston J. Frailty consensus: a call to action. J Am Med Dir Assoc. 2013;14(6):392-7. https:/doi.org/10.1016/j.jamda.2013.03.022

27. Vigorito C, Abreu A, Ambrosetti M, Belardinelli R, Corrà U, Cupples M, Davos CH, Hoefer S, lliou M-C, Schmid J-P, Voeller H, Doherty P. Frailty and cardiac rehabilitation: a call to action from the EAPC cardiac rehabilitation section. Eur J Prev Cardiol. 2016. https://doi.org/10.1177/2047487316682579

28. Tamuleviciute-Prasciene E, Drulyte K, Jurenaite G, Kubilius R, BjarnasonWehrens $B$. Frailty and exercise training: how to provide best care after cardiac surgery or intervention for elder patients with Valvular heart disease. Biomed Res Int. 2018;2018:1-36. https://doi.org/10.1155/2018/9849475

29. Eichler S, Salzwedel A, Harnath A, Butter C, Wegscheider K, Chiorean M, Voller $\mathrm{H}$, Reibis $\mathrm{R}$. Nutrition and mobility predict all-cause mortality in patients 12 months after transcatheter aortic valve implantation. Clinical research in cardiology : official journal of the German Cardiac Society. 2018; 107(4):304-11. https://doi.org/10.1007/s00392-017-1183-1 .

30. Bean JF, Orkaby AR, Driver JA. Geriatric rehabilitation shouldn't be an oxymoron: a path forward. Arch Phys Med Rehabil. 2019. https://doi.org/10. 1016/j.apmr.2018.12.038

31. Arjunan A, Peel NM, Hubbard RE. Feasibility and validity of frailty measurement in geriatric rehabilitation. Australas J Ageing. 2018;37(2):144-6. https://doi.org/10.1111/ajag.12502

32. Arjunan A, Peel NM, Hubbard RE. Gait speed and frailty status in relation to adverse outcomes in geriatric rehabilitation. Arch Phys Med Rehabil. 2018. https://doi.org/10.1016/j.apmr.2018.08.187

33. Calle A, Onder G, Morandi A, Bellelli G, Ortolani E, Perez LM, Mesas M, Sanniti A, Mazzanti P, Platto CN, Gentile S, Martinez N, Roque M, Inzitari M. Frailty related factors as predictors of functional recovery in geriatric rehabilitation: the sarcopenia and function in aging rehabilitation (SAFARI) multi-centric study. J Nutr Health Aging. 2018;22(9):1099-106. https://doi. org/10.1007/s12603-018-1060-2

34. van Dam van Isselt EF, van Wijngaarden J, Lok DJA, Achterberg WP. Geriatric rehabilitation in older patients with cardiovascular disease: a feasibility study. Eur Geriatr Med. 2018;9(6):853-61. https://doi.org/10.1007/s41999-0180119-2

35. Cruz-Jentoft AJ, Landi F, Schneider SM, Zuniga C, Arai H, Boirie Y, Chen LK Fielding RA, Martin FC, Michel JP, Sieber C, Stout JR, Studenski SA, Vellas B, Woo J, Zamboni M, Cederholm T. Prevalence of and interventions for sarcopenia in ageing adults: a systematic review. Report of the international sarcopenia initiative (EWGSOP and IWGS). Age Ageing. 2014;43(6):748-59. https://doi.org/10.1093/ageing/afu115

36. Chainani V, Shaharyar S, Dave K, Choksi V, Ravindranathan S, Hanno R, Jamal O, Abdo A, Abi Rafeh N. Objective measures of the frailty syndrome (hand grip strength and gait speed) and cardiovascular mortality: a systematic review. Int J Cardiol. 2016;215:487-93. https://doi. org/10.1016/j.ijcard.2016.04.068

\section{Publisher's Note}

Springer Nature remains neutral with regard to jurisdictional claims in published maps and institutional affiliations.

Ready to submit your research? Choose BMC and benefit from:
- fast, convenient online submission
- thorough peer review by experienced researchers in your field
- rapid publication on acceptance
- support for research data, including large and complex data types
- gold Open Access which fosters wider collaboration and increased citations
- maximum visibility for your research: over 100M website views per year
At BMC, research is always in progress.
Learn more biomedcentral.com/submissions

